\title{
PACMHCI V4 CSCW3 December 2020 Continued Editorial
}

\author{
JUHO KIM, KAIST, South Korea \\ SIÂN LINDLEY, Microsoft Research, UK \\ SARITA SCHOENEBECK, University of Michigan, USA
}

CCS Concepts: • Human-centered computing $\rightarrow$ Collaborative and social computing; $\bullet$ Information systems $\rightarrow$ Collaborative and social computing systems and tools.

\section{ACM Reference Format:}

Juho Kim, Siân Lindley, and Sarita Schoenebeck. 2020. PACMHCI V4 CSCW3 December 2020 Continued Editorial. Proc. ACM Hum.-Comput. Interact. 4, 3, Article 208 (December 2020), 1 page. https://doi.org/10.1145/ 3432907

We are delighted to present this issue of the Proceedings of the ACM on Human-Computer Interaction, which contains scholarship from the Computer-Supported Cooperative Work and Social Computing ( $\mathrm{CSCW}$ ) community. This is the third issue that represents the new quarterly submission model. This issue has 67 papers, 19 from the January 2020 round and 48 from the June 2020 round. This issue represents the contributions of external reviewers, Associate Chairs, and the Editors, all of whom continue to carry out a high-quality review process during a global pandemic. As Papers Chairs, we are grateful for the community's shared efforts to continue shaping and disseminating CSCW's tradition of high-quality scholarship.

Authors' addresses: Juho Kim, juhokim@kaist.ac.kr, KAIST, South Korea; Siân Lindley, sianl@microsoft.com, Microsoft Research, UK; Sarita Schoenebeck, yardi@umich.edu, University of Michigan, USA.

Permission to make digital or hard copies of part or all of this work for personal or classroom use is granted without fee provided that copies are not made or distributed for profit or commercial advantage and that copies bear this notice and the full citation on the first page. Copyrights for third-party components of this work must be honored. For all other uses, contact the owner/author(s).

(C) 2020 Copyright held by the owner/author(s).

2573-0142/2020/12-ART208

https://doi.org/10.1145/3432907 